\title{
Sinanköy (Lalapaşa-Edirne) ve Çevresinin Yapısal Jeomorfoloji Özelliklerinin Drenaj Sistemi Üzerindeki Etkileri
}

\section{The Effects of Structural Geomorphology Features on Drainage System in Sinanköy (Lalapaşa-Edirne) and Its Surroundings}

\author{
Tunahan AYKUT ${ }^{1} \oplus$, Hüseyin TUROĞLU ${ }^{2}$ (]
}

'İstanbul Üniversitesi, Sosyal Bilimler Enstitüsü, Coğrafya Bölümü, İstanbul, Türkiye

${ }^{2}$ İstanbul Üniversitesi, Edebiyat Fakültesi, Coğrafya Bölümü, İstanbul, Türkiye

ORCID: T.A. 0000-0003-0503-3859; H.T. 0000-0003-0173-6995

\section{öz}

Sinanköy (Lalapaşa-Edirne) ve çevresinde gerçekleştirilen bu çalışmanın amacı; çalışma sahasının yapısal jeomorfoloji özelliklerini belirlemek ve bu özelliklerin drenaj sistemi üzerindeki etkilerini araştırmaktır. Araştırmanın amacı doğrultusunda, sahanın yapısal özellikleri incelenmiş; morfometrik analizler, çizgisellik analizi, hidrolojik analizler yapılmıştır.Arazi çalışmaları iki yönlü gerçekleştirilmiştir. Bu kapsamda, hem CBS teknolojileri ile gerçekleştirilen analizlerin sonuçları ve bulguların arazide kontrol edilmesi ve doğrulama çalışmaları, hem de yapısal jeomorfoloji kapsamında ölçümlerin yapılması, fotoğraf çekimi ve haritalama uygulamaları yapılmıştır. Analizler ve saha çalışmalarına ait ölçüm sonuçlarına göre; jeolojik formasyonların genel olarak kuzeybatı-güneydoğu doğrultulu olduğu, tabakaların genel dalış yönünün güneybatı yönlü olduğu, eğim açılarının ise $5-30^{\circ}$ arasında değiş̧iği belirlenmiştir. Analiz sonuçları ve saha çalışmalarına ait ölçümler; monoklinal yapı jeomorfolojisini açıkça ortaya koymuştur. Konsekant ve resekant akarsuların, monoklinal yapının doğal eğim doğrultusuna uyarak kuzeydoğu-güneybatı doğrultusunda akış gösterdikleri, sübsekant akarsuların doğal eğim yönünden saparak doğu-batı doğrultusu kazandıkları, obsekant akarsuların ise doğal eğim doğrultusunun tersine doğru kuzeybatı-güneydoğu doğrultusunda aktıkları belirlenmiştir. Drenaj ağının gelişim süreci, monoklinal yapının jeomorfolojik, litolojik ve stratigrafik özelliklerinden etkilenmiş, bu etkilenmeye bağlı flüviyal gelişiminse zamanla monoklinal yapının elemanter yer şekillerini daha belirgin olarak ortaya çıkmasına imkân vermiştir. Bu durum; monoklinal yapı jeomorfolojisini tipik hale getirirken, drenaj sisteminin de yapıya uyumlu“kafesli (ortogonal)" bir drenaj ağı karakteri kazanmasına neden olmuştur.

Anahtar kelimeler: Yapısal Jeomorfoloji, Monoklinal Yapı, Drenaj Sistemi

\section{ABSTRACT}

The main aim of this study is to determinate structural geomorphology features and research their effects on the drainage system. Firstly, $1 / 25.000$ scale topographic map and 1/100.000 scale geological map were digitized on the Geographical Information Systems platform and a digital database was created. Structural features were examined; morphometric analyzes, lineament analyze and hydrological analyses were performed. In the field works; verification and correction of the GIS-based analyze results, measurements of structural features, photographing and mapping studies have been carried out. According to GIS-based analyze and measurement results; geological formations general strike is northwest-southeast, prevalent dip direction is southwest and dip angle values varying between $5-30^{\circ}$. Morphometric analyze results and field measurements, clearly defined the monoclinal structure geomorphology. It has been seen that "consequent" and "resequent "streams flow through northeast-southwest, parallel to the monoclinal structures' natural slope direction, while "obsequent" and "subsequent" streams flow through west-east and northwest-southeast, deviating from the monoclinal structures natural slope direction. The evolutionary process of the drainage system has been affected by monoclinal structures' geomorphologic, lithologic and stratigraphic characteristics. This influence also has controlled the exhumation of the subjacent structure, made the monoclinal structure landforms more evident. As a result of these processes, the drainage system gained a "trellis (orthogonal)" pattern that is compatible with the structure.

Keywords: Structural Geomorphology, Monoclinal Structure, Drainage System

Başvuru/Submitted: 25.07.2019 • Revizyon Talebi/Revision Requested: 16.10.2019 • Kabul/Accepted: 22.10.2019• 


\section{EXTENDED ABSTRACT}

Litospheres' structural features, impact drainage systems establishment characteristics. Structurally weaker zones determine river courses and their lineation properties. Strike, dip direction and dip angle features of the geological layers and resistance characteristics of the rocks against erosion and weathering, effects fluvial processes behaviors. Thus, different landscapes with different structural properties evoke to the establishment of different and distinctive drainage systems. The study area is located approximately $20 \mathrm{~km}$ northeast of the Edirne city center. From the geological perspective; the study area is located at the border of Thrace Sedimentary Basin and Strandzha Massif. The most important features that controlled and orientated drainage system characteristics were the structural geomorphology features. Hence, the main aim of this research includes the determination of structural geomorphology features, investigation for pieces of evidence for the monoclinal structure and its distinctive drainage system in Sinanköy (Lalapaşa-Edirne) and its surroundings.

To determine the structural geomorphology features of the study area, 1/25.000 scale topographic map and 1/100.000 scale geological map were digitized on the Geographical Information Systems platform and a digital database was created. 5.00-meter resolution digital elevation model was acquired and morphometric analyses were performed. In the field works, using "Brunton Type Geological Compass", measurements of the strike, dip direction and dip angle features of geological layers were performed. Thickness values of geological layers were measured using a qualified tape measure. All these analyses were compared with the field work impressions and the structural geomorphology characteristics were determined, photographed and mapped. Rose diagrams of the measurements, were used as statistical graphics. "Hydrology" module of Arcgis 10.2 was used to define drainage systems' general properties. First; flow direction of the study area determined, then with flow accumulation analyze, surface drainage network was produced. GIS-based hydrology analyzes and the topographic maps have been compared and probable mistakes have been eliminated.

Morphometric analyses, hydrologic analyses and field work measurement results showed us that while layers general strike is northwest-southeast, prevalent dip direction is southwest and dip angle values varying between $5-30^{\circ}$. The alternating character of lithological units with different strength was observed clearly in the field works. Morphometric analyze results and field measurements, clearly defined the monoclinal structure geomorphology. It has been seen that "consequent" and "resequent" streams flow through northeast-southwest, parallel to the monoclinal structures' natural slope direction, while "obsequent" and "subsequent" streams flow through west-east and northwest-southeast, deviating from the monoclinal structures natural slope direction. Tectonic deformation and geological layers thickness, strike, dip direction and dip angle values altogether reflect typical monoclinal structure in the study area. Fluvial processes and drainage behavior have shaped and sculptured the landscape with "cuesta fronts", "dip slopes", "consequent depressions", "subsequent depressions", "obsequent depressions" and "resequent depressions" as typical monoclinal structure landforms.

In this study; structural geomorphology features and drainage characteristics were investigated in Sinanköy (Lalapaşa-Edirne) and its surroundings. Statistical diagrams of the measurements, representing the evidence for the interaction between structure and the drainage system. Results of the GIS-based analyzes supporting the existence of cuesta relief and its exclusive drainage system. The evolutionary process of the drainage system has been affected by monoclinal structures geomorphologic, lithologic and stratigraphic characteristics. This influence also has controlled the exhumation of the subjacent structure, made the monoclinal structure landforms more evident. As a result of these processes, the drainage system gained a "trellis (orthogonal)" pattern that is compatible with the structure. 


\section{GíRIŞ}

Drenaj sistemleri, gelişimleri boyunca üzerinde kuruldukları katı arzın yapısal özelliklerinden etkilenirler. Tabakalı olup olmamaları, tabakaların duruşları, uzanış doğrultuları, eğim özellikleri, kayaların aşınıma karşı direnç özellikleri akarsu drenaj sistemlerinin şekillenmesinde rol alan, belirleyici olan yapısal özelliklerdir. Bu nedenle; yatay, monoklinal, kıvrıml, domlu, kırıklı yapılar üzerinde kendilerine özgü akarsu drenaj sistemleri gelişir. Bir başka ifadeyle; drenaj sistemleri, akarsuların dağılış desenleri de büyük oranda o sahanın yapısal özelliklerini yansıtır (Davis, 1899; Schumm, 1956; Yalçınlar, 1958; Kurter, 1967; Morisawa, 1987; Summerfield, 1991; Twidale, 2004; Andreani vd., 2014; Erinç, 2015; Aykut, 2018; Paul vd., 2018; Petit vd., 2018).

Çalışma alanı, Edirne il merkezinin yaklaşık $20 \mathrm{~km}$ kuzeydoğusunda, kabaca Doğu 26'41' - 26'44' ve Kuzey 41'47' - 41'49' koordinatları arasında,jeolojik perspektifte Istranca Masifi ile Trakya Sedimanter Havzası'nın sınırında yer almaktadır (Şekil 1). Bu çalışmanın amacı; Sinanköy ve çevresinde, yapısal jeomorfoloji özellikleri, yüzeysel drenaj ağ etkileşimi ve jeomorfolojik delillerini araştırmaktır. Çalışma kapsamında; sahanın yapısal özellikleri ana hatlarıyla ele alınmıştır. Yapısal jeomorfoloji özelliklerinin belirlenmesi, monoklinal yap1 morfolojisinin ve bu jeomorfolojinin tipik drenaj sistemini tanımlayan deliller araştırılmıştır. Bu kapsamda; araştırma sahasının morfometrik analizleri, arazi ölçümleri, analiz ve ölçüm sonuçlarının ilişkilendirilerek yorumlamaları ve tespitlerin arazi kontrolleri yapılmıştır.

\section{MATERYAL VE METOT}

Yapısal jeomorfoloji özelliklerinin belirlenmesi için öncelikle 1/25.000 ölçekli topoğrafya haritasının Coğrafi Bilgi Sistemleri (CBS) ortamında sayısallaştırılması ile topografik veri tabanı oluşturulmuştur. Sahanın litolojik birimlerinin dağılış özelliklerinin belirlenmesi için ise 1/100.000 ölçekli jeoloji haritası kullanılmıştır. CBS, ArcGIS 10.2 imkânları ile 5.00 metre yersel çözünürlüklü sayısal yükselti modeli elde edilmiş, çalışmaya katkı sağlayacak yüzey analizleri ve morfometrik analizler gerçekleştirilmiştir. Eğim analizi, hipsometrik integral, yüzey indeksi, yüzey engebeliliği, akarsu uzunluk-gradyan indeksi (SL İndeksi), vadi tabanının vadi genişliğine oranı ( $V f$ Indeksi) bu kapsamda uygulanan CBS analizlerinden bazılarıdır. Ayrıca Geomatica 2015 yazılımı kullanılarak çizgisellik analizi yapılmıştır. Çalışma sahasındaki drenaj ağının belirlenmesi için CBS ArcGIS 10.2 yazılımının "Hydrology" modülü kullanılarak; sahadaki "doğal akım yönleri", "doğal akım toplanma" verisi üretilmiş, sonuçlar $1 / 25000$ ölçekli topografya haritasındaki drenaj verisi ile ilişkilendirilerek olası doğrulama kontrolleri yapılmıştır.

Saha çalışmalarında ise Sinanköy ve çevresindeki tabakaların doğrultu, eğim açısı ve eğim yönü özellikleri "Brunton Tipi Jeolog Pusulası" kullanılarak ölçülmüştür. Tabakaların kalınlık ölçümleri ise uygun nitelikteki şerit metre kullanılarak gerçekleştirilmiştir. Ayrıca, hem morfometrik analiz sonuçları hem de ArcGIS Hidroloji analizi sonuçlarının arazi kontrolleri ile fotoğraf çekimleri, arazi çalışması sırasında gerçekleştirilen diğer çalışmalardır.

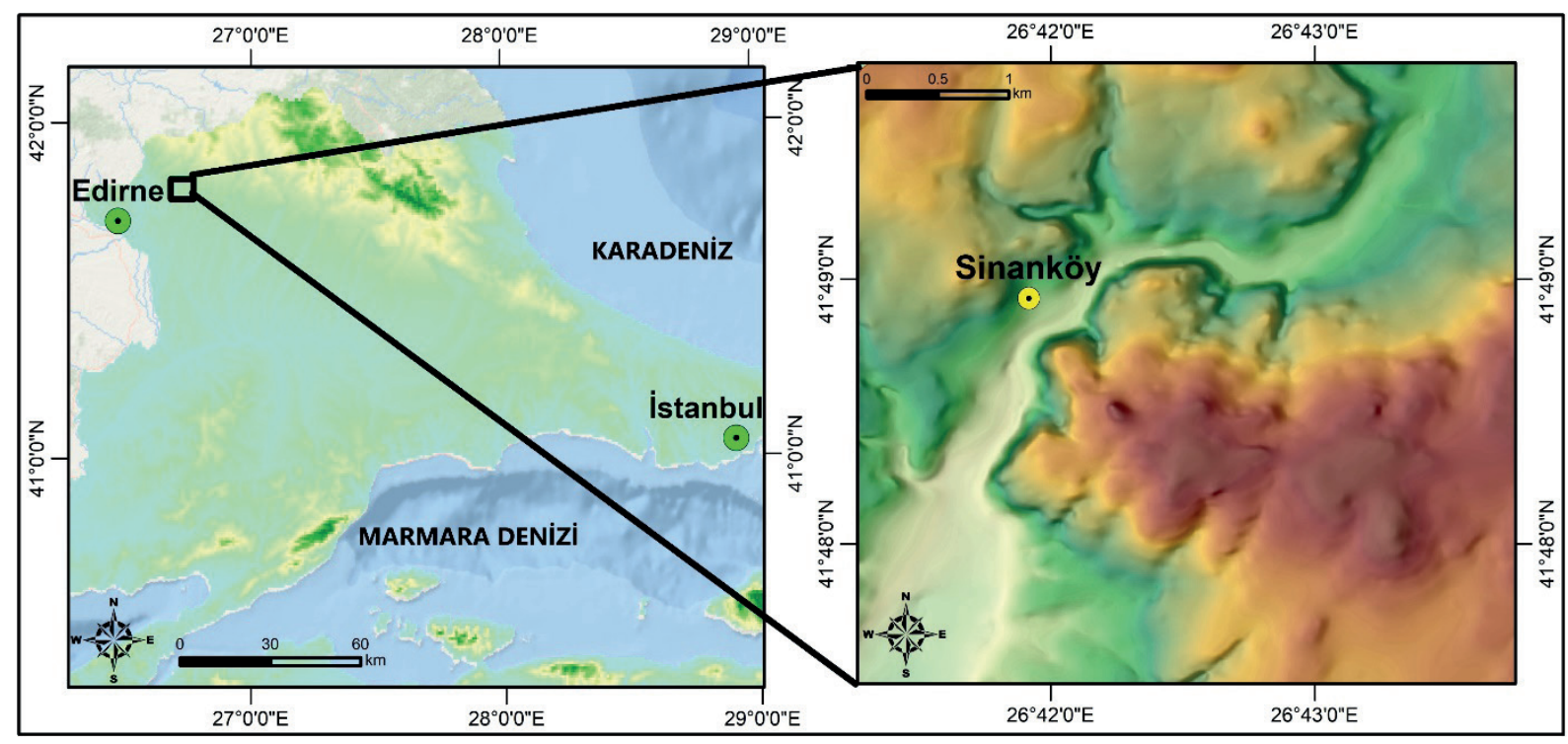

Şekil 1: Çalışma sahasının lokasyon özellikleri.

Figure 1: Location features of the study area. 
Analiz sonuçları; bir istatistiksel grafik aracı olan gül diyagramı ile görselleştirilmiştir. Yapısal jeomorfoloji özelliklerinin şematik çizimleri CorelDRAW X7 yazılımı kullanılarak yapılmıştır.

\section{Genel Yapısal Özellikler}

Çalışma alanı; Eosen'den Kuvaterner'e kadar kesintisiz devam eden sedimanter birimlerden oluşmaktadır (Şekil 2). İslambeyli Formasyonu ve Kırklareli Kireçtaşı sahadaki Eosen birimlerini oluşturur (Çağlayan ve Yurtseven, 1998; MTA, 2006; Şans, 2018). İslambeyli Formasyonu; sahanın kuzeyindeki Paleozoik Istranca Masifi üzerine transgresif olarak gelen serinin ilk sedimanter birimlerini teşkil etmektedir (Çağlayan ve Yurtseven, 1998; MTA, 2006; Şans, 2018). Genel olarak kumtaş1kiltaşı-marn-tüfit ardalanmasından meydana gelmektedir (Çağlayan ve Yurtseven, 1998; MTA, 2006; Şans, 2018). Kırklareli Kireçtaşı; sığ denizel ortamda çökelmiş resifal kireçtaşlarını temsil etmektedir ve saf kireçtaşı-killi kireçtaş1kumlu ve çakı1llı kireçtaşı gibi ardalanmalarla karakterize olmaktadır (Çağlayan ve Yurtseven, 1998; MTA, 2006; Şans, 2018) (Şekil 2). Oligosen'e ait olan Süloğlu Formasyonu; lagüner ortamda çökelmiş kum-silt-kil matriksli kiltaşı-şeylkumtaşı-miltaşı gibi birimlerden oluşur (Çağlayan ve Yurtseven, 1998; MTA, 2006; Şans, 2018). Miyosen Ergene Formasyonu; konglomera mercekli kiltaşı-kumtaşı birimlerini barındırmaktadır (Çağlayan ve Yurtseven, 1998; MTA, 2006; Şans, 2018). Pliyosen Trakya Formasyonu ise, çakıl-kum-kil matriksli çakıltaşı-kumtaşı-kiltaşı birimlerinden oluşmaktadır (Çağlayan

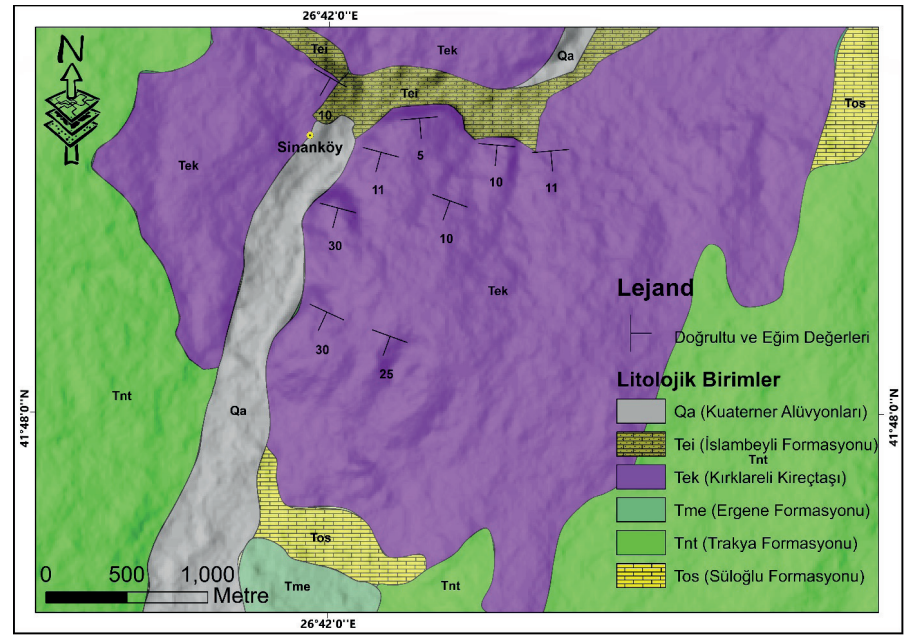

Şekil 2: Sahanın litolojik birimleri ve saha çalışmalarında ölçülen tabaka doğrultu ve eğim değerleri (Litolojik birimler için Çağlayan ve Yurtseven,1998'den yararlanılmıştır).

Figure 2: Lithological units of the study area and layers direction and dip values measured in field works (Çağlayan and Yurtseven, 1998 were used for lithological units). ve Yurtseven, 1998; MTA, 2006; Şans, 2018) (Şekil 2). Çalışma sahasındaki Kuvaterner alüvyonları ise akarsu boyu genç birikimleri ile temsil edilir (Çağlayan ve Yurtseven, 1998; MTA, 2006; Şans, 2018).

Trakya Sedimanter Havzası'nın, Tersiyer boyunca genişlemeli tektonik rejimi altında açılmaya başladığı ve sedimanter birimlerin havza gelişiminin kontrolünde geliştiği birçok bilimsel yayında ifade edilmiştir (Keskin, 1974; Turgut ve Atalık, 1988; Yılmaz, 1988; Perinçek, 1991; Dimitriadis, vd., 1998; Burchfiel vd., 2008; Kilias vd., 2011; Selim, 2013). Bölgenin yapısal jeomorfoloji özelliklerine ise çeşitli yayınlarda farklı kapsamlarda değinilmiştir (Ardel ve Tümertekin 1956; Ardel, 1957; Yalçınlar, 1958; Kurter, 1967; Kurter, 1978; Kurter, 1982; Ardos, 1995). Bu yayınlar incelendiğinde çalışma sahası yapısal jeomorfolojisi hakkında aşağıdaki gibi genel bir değerlendirme yapılabilir. Saha; Tersiyer'den itibaren havza merkezinde görülen sübsidans ve kenar faylarının hareketinden oldukça etkilenmiştir. Bölgede etkili olan genişleme tektonik rejimi; Ergene havzasında çökme ve bu çökmeye müsaade eden, ya da teşvik eden kenar faylarının oluşmasında başrolü oynamıştır. Ergene havzasındaki sübsidans ve kuzeyini sınırlayan kenar fayları yatay konumdaki tabakaların sübsidansa bağlı olarak, havza merkezine doğru eğimlenerek, monoklinal bir karakter kazanmasına neden olmuştur.

\section{ANALIZLLER VE BULGULAR}

\subsection{Morfometrik Analizler}

Morfometrik analizler, bir alanın genel jeomorfolojik karakteri hakkında çıkarım yapmak amacıyla sıklıkla kullanılmaktadır ve jeomorfoloji çalışmalarında büyük öneme sahiptir (Strahler, 1952; Turoğlu, 1997;Keller ve Pinter, 2002; Özdemir, 2011; Yıldırım, 2014; Azanon vd., 2015; Rana vd., 2016; Aykut, 2019; Turoğlu ve Aykut, 2019). Bu çalışmada da sahanın yapısal jeomorfoloji özellikleri hakkında genel bilgi sahibi olmak ve altyapı teşkil etmesi amacıyla yüzey analizleri ve morfometrik analizler uygulanmıştır. Morfometrik analizlerin uygulanmasında; topoğrafya haritalarından üretilmiş sayısal veritabanı kullanılarak, 5 metre yersel çözünürlükte sayısal yükselti modeli altlık olarak kullanılmıştır.

Hipsometrik Integral; referans alınan düz bir alan üzerinde kalan kara kütlesinin hacminin dağılımı hakkında bilgi verir (Strahler, 1952). Bu integral, bir alan için aşağıda verilen Denklem (1) ile hesaplanmaktadır (Pike ve Wilson, 1971). Çalışma sahasında özellikle sübsekant akarsuların gömülme 


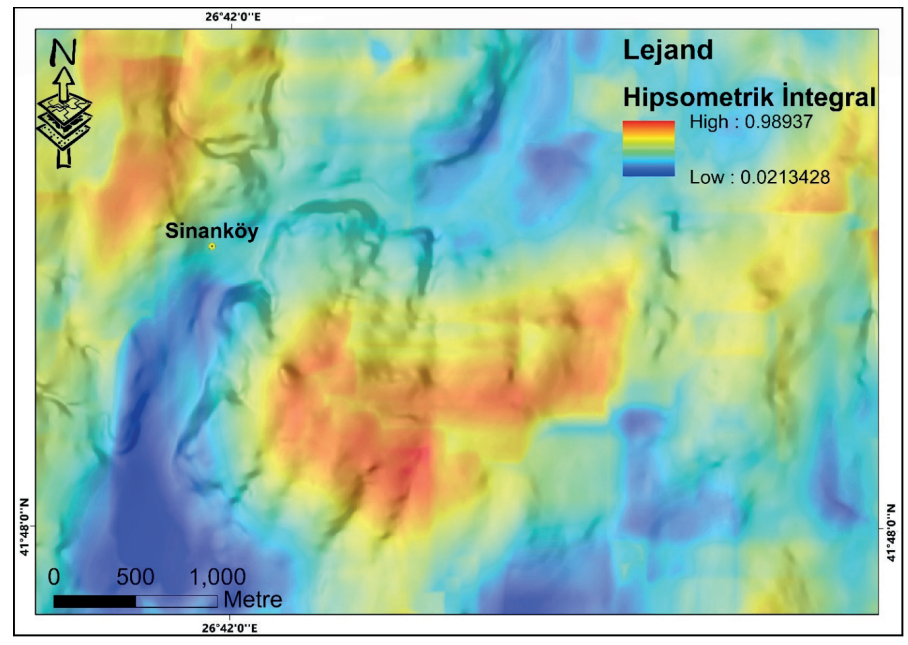

Şekil 3: Çalışma sahasının Hipsometrik İntegral değerlerinin dağılış özellikleri.

Figure 3: The distribution features of Hypsometric Integral values in the study area.

oranlarının yüksek olduğu sübsekant depresyonlarda, hipsometrik integral değerlerinin düşük seviyelerde seyrettiği göze çarpmaktadır (Şekil 3).

$$
H I=\frac{h_{\text {ortalama }}-h_{\text {minimum }}}{h_{\text {maximum }}-h_{\text {minimum }}}
$$

Buna ek olarak, kuesta cephelerinde özellikle obsekant akarsuların açtığı obsekant depresyonlarda ortalama-yüksek seviyelerde gözlenen hipsometrik integral değerleri, aynı zamanda kuesta cephelerinin yamaç süreçleri ile geriletildiği bir dinamik süreçler dizisine işaret etmektedir.

Yüzey Engebeliliği; iki boyutlu düz bir yüzeyin belirli bir yükseltiye ve dolayısıyla eğime sahip üç boyutlu bir yüzeye oranını ifade eder. Yüzey Engebeliliği'ni ölçmek için farklı yaklaşımlar mevcuttur. Bu çalışmada; Andreani ve arkadaşları (2014) tarafindan kullanılan yöntem kullanılmıştır. Bu yönteme göre Denklem (2) ile bir sahanın yüzey engebeliliği hesaplanabilir.

$$
S R=\frac{T S}{F S}
$$

Burada $S R$ yüzey engebeliliğini ifade ederken, $T S$ analiz edilen topoğrafik yüzeyi ve $F S$ düz ve yatay yüzeyleri ifade eder. Düşük değerler düz ve düze yakın alanlara karşılık gelirken, değer yükseldikçe yüzey düzlüğünü kaybeder ve akarsu aşındırma ve gömülme oranları arttıkça engebelilik oranı da yükselir (Andreani vd., 2014). Engebelilik değerlerinin, özellikle Sinanköy Kuestası'nın cephesinde maksimuma ulaştığı görülmektedir (Şekil 4).

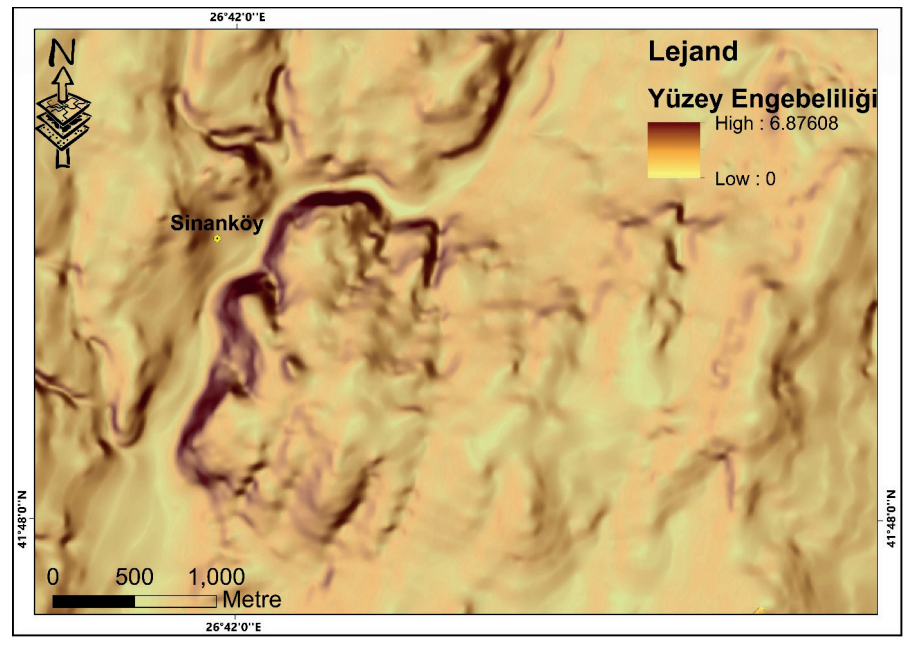

Şekil 4: Yüzey Engebeliliği değerleri dağılış haritası.

Figure 4: The distribution map of Surface Roughness values.

Yüzey Indeksi;Andreani ve arkadaşları (2014) tarafindan ortaya konmuştur ve esas olarak hipsometrik integral, yüzey engebeliliği ve yükseklik faktörlerini temel alır. Bu morfometrik indis; akarsu taban seviyesi değişiklikleri, litolojik farklılıklar, tektonik hareketler gibi etkilere tepki olarak yatağını derinleştiren akarsuların gömülme dereceleri hakkında fikir verir. Andreani ve arkadaşlarına (2014) göre bir alanın yüzey indeksi Denklem (3) ile hesaplanabilmektedir.

$$
\text { SI }\left(\frac{H I-H I_{\min }}{H I_{\max }-H I_{\min }}\right) x\left(\frac{h-h_{\min }}{h_{\max }-h_{\min }}\right) \quad\left(\frac{S R-S R_{\min }}{S R_{\max }-S R_{\min }}\right)
$$

Burada $S I$ yüzey indeksini temsil ederken $H I, h$ ve $S R$ sırasıyla hipsometrik integral, yükseklik ve yüzey engebeliliğini ifade eder. Pozitif SI değerleri genel olarak gömülmenin düşük olduğu alanları ifade ederken, negatif $S I$ değerleri gömülmenin yüksek olduğu ve yüksek $S R$ değerlerinin görüldüğü bölgeleri yansitir.

Yüzey indeksi değerleri; gömülmenin fazla olduğu sübsekant depresyonlar, konsekant depresyonlar ile obsekant depresyonlarca oldukça yoğun yarılmış bulunan kuesta cephesinde negatif değerler sergilemektedir. Pozitif değerler ise Sinanköy Kuestası'nın sırtı ile nispeten az yarılmış bulunan tabaka sırtlarında görülmektedir (Şekil 5).

Eğim Değerleri; CBS ortamında hesaplanmıştır. Yüzey engebeliliği değerleriyle paralellik göstermek suretiyle,eğim değerleri özellikle Sinanköy Kuestası'nın cephesinde 30 derecenin üzerine çıkmaktadır. Eğim değerlerinin ortalamaların üstüne çıktığı diğer yerler ise obsekant ve resekant akarsuların açtıkları çentik vadilerin yamaçlarıdır. Vadiler arasında kalan ve 


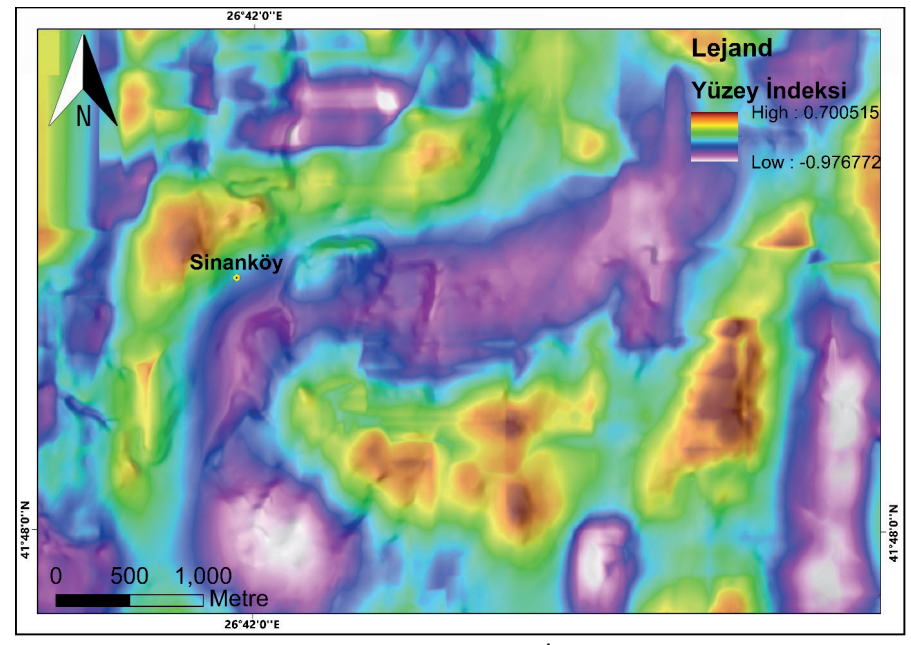

Şekil 5: Çalışma sahasında Yüzey İndeksi Değerlerinin dağılış özellikleri.

Figure 5: The distribution features of Surface Index values in the study area.

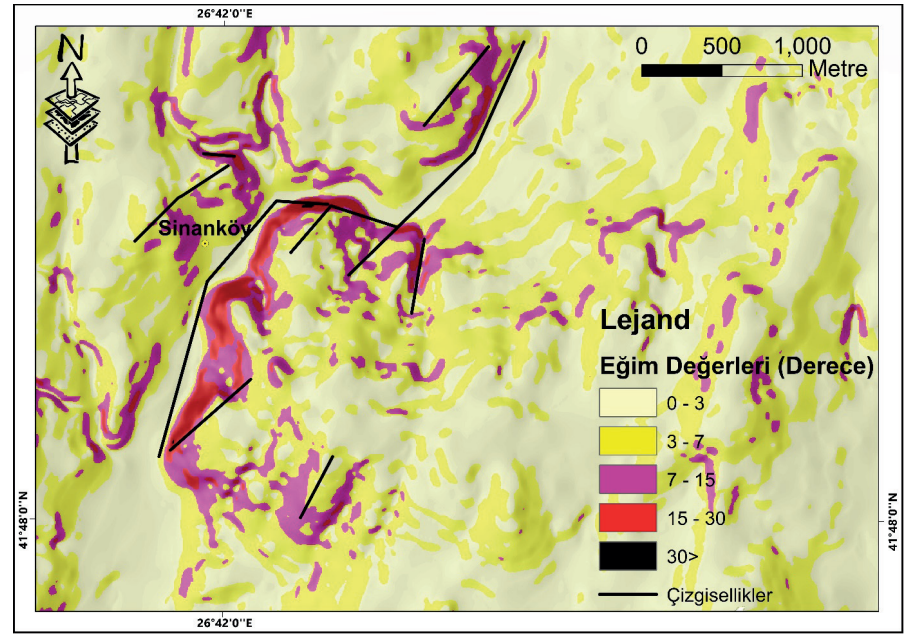

Şekil 6: Çalışma sahasının eğim sınıflaması, çizgisellikler ve onların dağılış özellikleri.

Figure 6: Slope classification of the study area, lineaments and their distribution characteristics.

tabaka sırtlarının az yarılmış kısımlarında değerlerin minimuma indiği görülmektedir (Şekil 6).

Çizgisellik Analizi; yapısal jeomorfoloji çalışmalarında büyük öneme sahiptir ve yeryüzündeki mevcut prosesin yorumlanmasında yoğun olarak kullanılmaktadır. Sahadaki çizgisellikler, 5.00 metre çözünürlüğe sahip sayısal yükselti modelinden üretilen kabartma haritasının Geomatica 2015 programının "Çizgisellik Algoritması" kullanılarak, otomatik olarak üretilmiştir. Çizgiselliklerin genel olarak akarsular tarafından oluşturulmuş oldukları ve doğal eğim doğrultusu ile paralellik gösterdikleri görülmektedir (Şekil 6).

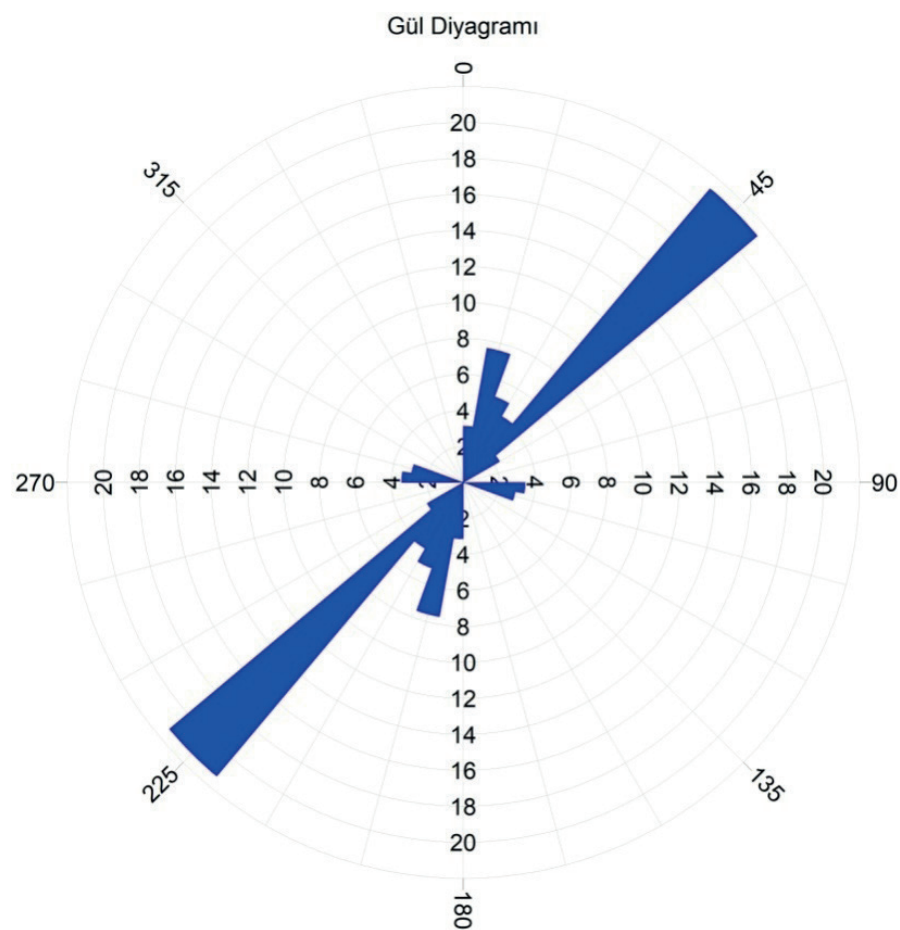

Şekil 7: Çalışma sahasındaki çizgiselliklerin gül diyagramı. Figure 7: Rose diagram of lineaments in the study area.

SLİndeksi; akarsu kanalının istenilen bir bölümü için Denklem (4) ile hesaplanabilmektedir (Keller ve Pinter, 2002).

$$
S L=\left(\frac{\Delta H}{\Delta L}\right) \cdot L
$$

$\mathrm{Bu}$ denklemde $S L$; akarsu uzunluk-gradyan indeksini tanımlarken, $\Delta H / \Delta L$ kanal eğimini, $L$ ise hesaplanmak istenen kanal parçasından kaynak kısmındaki en yüksek noktaya kadar olan mesafeyi tanımlar. İndeks değerleri çalışma alanında düşük değerler göstermektedir (Şekil 8). Aktif tektoniği tanımlayacak herhangi bir anomaliye rastlanmamıştır.

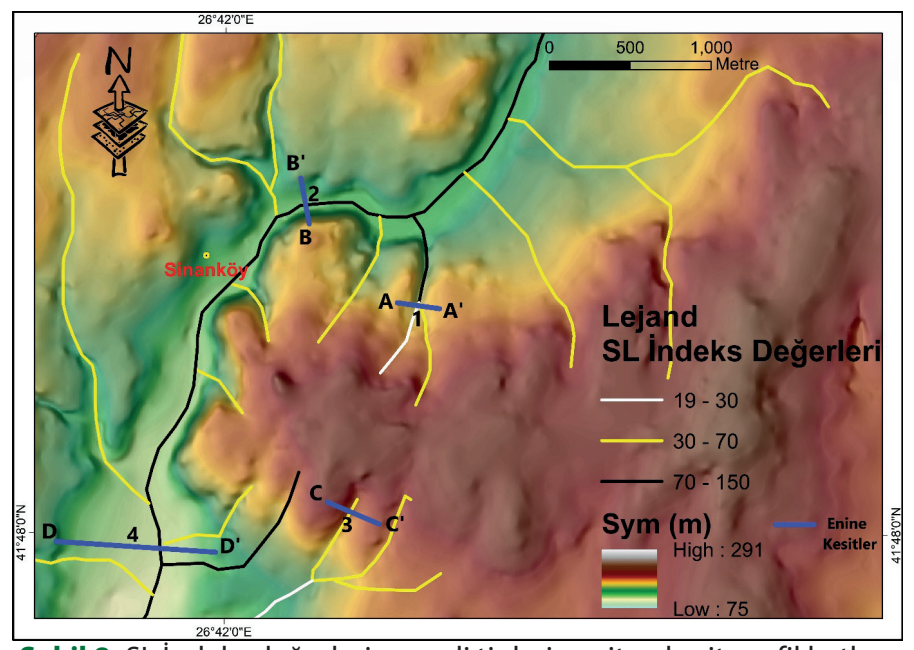

Şekil 8: SL İndeks değerleri ve vadi tiplerine ait enkesit profil hatları. Figure 8: SL Index values and cross-section profile lines belonging to the valley types. 
Vf İndeksi; yapısal özelliklerin yamaç üzerindeki etkileri konusunda fikir edinmek amacıyla kullanılmaktadır (Bull, 1977). Vadi tabanı genişlikleri; kayaların dirençliliklerinin azalması, havza alanının artması ve yükselme (uplift) oranlarının düşmesiyle birlikte artarken, vadi yükseklikleri ise yükselmenin kesilmesinden sonra geçen zaman içinde azalır (Bull, 1978). Bull, (1977)'ye göre indeks, Denklem (5) ile hesaplanabilmektedir.

$$
V f=\frac{2 V f w}{(E l d-E s c)+E r d-E s c)}
$$

Bu denklemde $V f$; vadi tabanı genişliği-vadi yüksekliği oranını ifade ederken, $V f w$; vadi tabanı genişliğini, Eld; sol yamacın yüksekliğini, $E r d$; sağ yamacın yüksekliğini, Esc ise vadi tabanının yüksekliğini ifade etmektedir. Çalışma sahasında; obsekant, resekant, sübsekant ve konsekant akarsu vadilerinden enine kesitler çıkarılmıştır. Bu kesitler kullanılarak $V f$ oranları hesaplanmıştır. Buna göre sübsekant ve konsekant depresyonlarda değerler sırasıyla 6.93 ve 6.12 olarak karakterize olmaktayken, obsekant ve resekant depresyonlarda değerler sirasiyla 0.55 ve 1.81 olarak hesaplanmıştır. Bu değerler; sübsekant ve konsekant depresyonların yamaçlarının yamaç süreçleri ile nispeten daha fazla geriletilmiş olduklarını ve tabanlarının daha fazla genişletildiğini, obsekant ve resekant depresyonların ise daha dik yamaçlı ve dar tabanlı bir karakter taşıdıklarını göstermektedir (Tablo 1; Şekil 8,9).

Tablo 1: Farklı vadi tiplerini tanımlayan en kesitlerin Vf İndeks değerleri.

Table 1: Vf Index values of cross sections which define different valley types.

\begin{tabular}{cc}
\hline Vadi enkesit numaraları & Vf indeksi \\
1 nolu vadi enkesiti & 0,55 \\
2 nolu vadi enkesiti & 6,93 \\
3 nolu vadi enkesiti & 1,81 \\
4 nolu vadi enkesiti & 6,12 \\
\hline
\end{tabular}

\subsection{Saha Ölçümleri}

Saha çalışmalarına ait ölçüm sonuçlarına göre; Sinanköy ve çevresindeki litolojik formasyonlara ait tabakaların genel olarak kuzeybatı-güneydoğu doğrultulu olduğu, tabakaların genel dalış yönünün güneybatı yönlü olduğu, eğim açılarının ise 5-30 arasında değiştiği gözlenmiş ve ölçülmüştür (Fotoğraf 1, Şekil 10). Tabaka doğrultusunun $0^{\circ}$ kuzey ile yaptığı açı temel alınarak, tabaka doğrultu ölçümleri gerçekleştirilmiştir. Buna göre tabaka doğrultularının $80^{\circ}$ ile $120^{\circ}$ arasında değiştiği görülmektedir. Eğim açıları kısa mesafelerde değişim göstermekte olup, yaygın

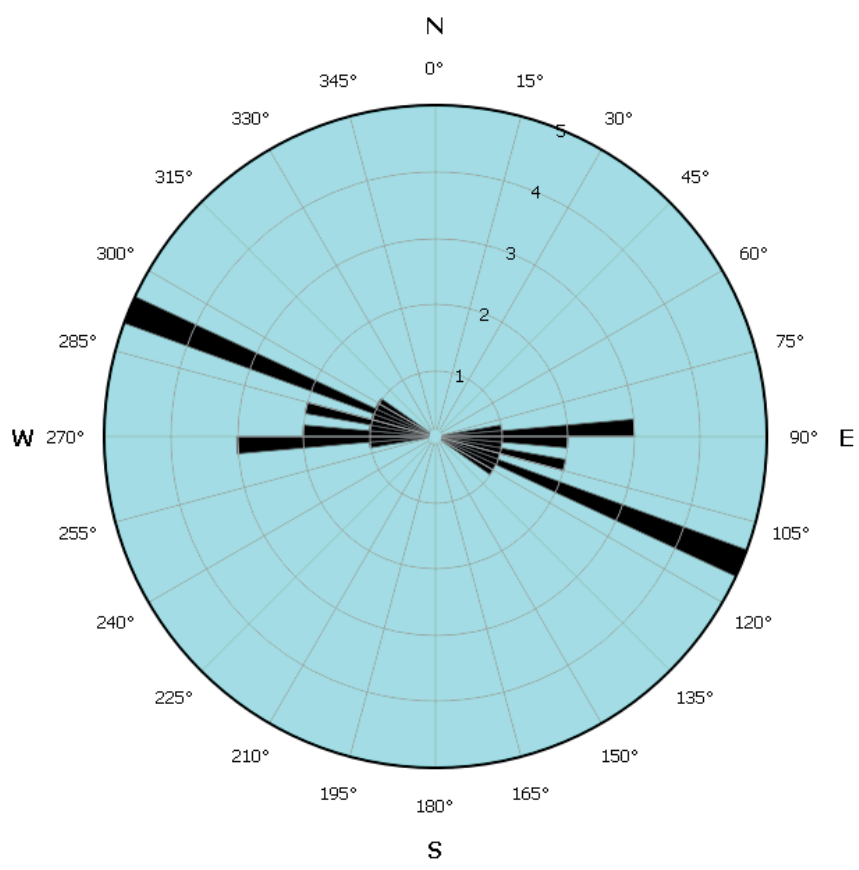

Şekil 10: Tabakaların uzanış doğrultularını temsil eden gül diyagramı.

Figure 10: Rose diagram representing the directions of layers.

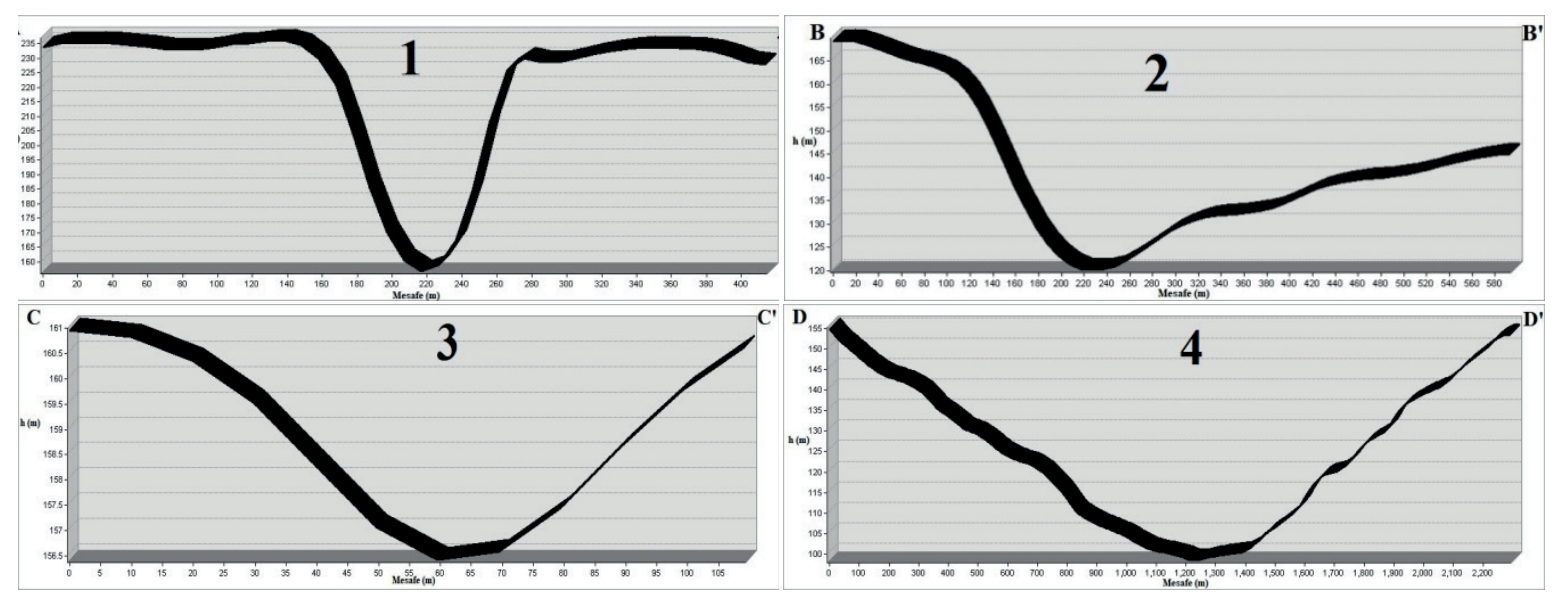

Şekil 9: Farklı vadi tiplerini tanımlayan en kesitler: 1: Obsekant kesit; 2: Sübsekant kesit; 3: Resekant kesit; 4: Konsekant kesit. Figure 9: Cross sections of different valley types: 1: Obsequent section; 2: Subsequent section; 3: Resequent section; 4: Consequent section. 


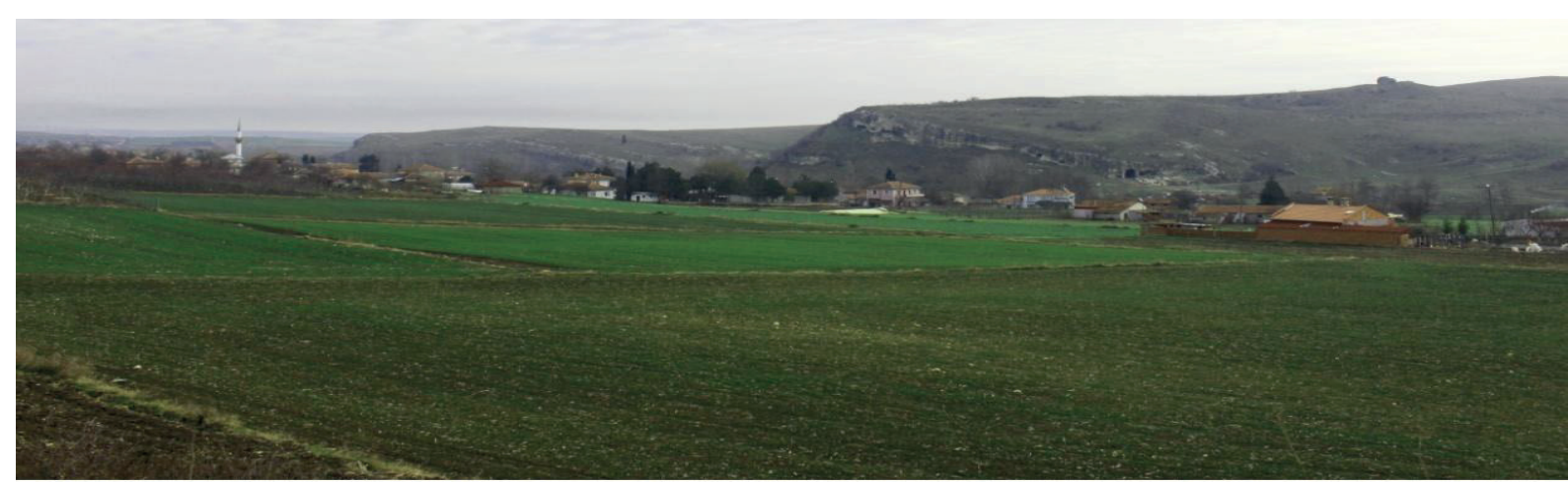

Fotoğraf 1: Sinanköy çevresindeki kuesta rölyefi.

Photo 1: Cuesta relief around Sinanköy.

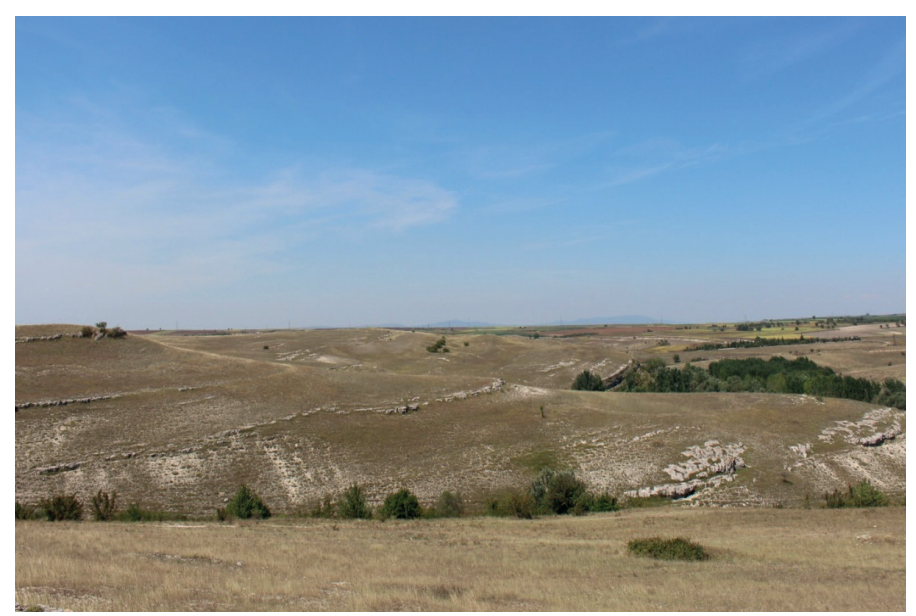

Fotoğraf 2: Monoklinal yapı ve Sinanköy Kuestası'nın doğu bölümü (Batıya bakış).

Photo 2: Monoclinal structure and east part of Sinanköy Cuesta (Looking west).

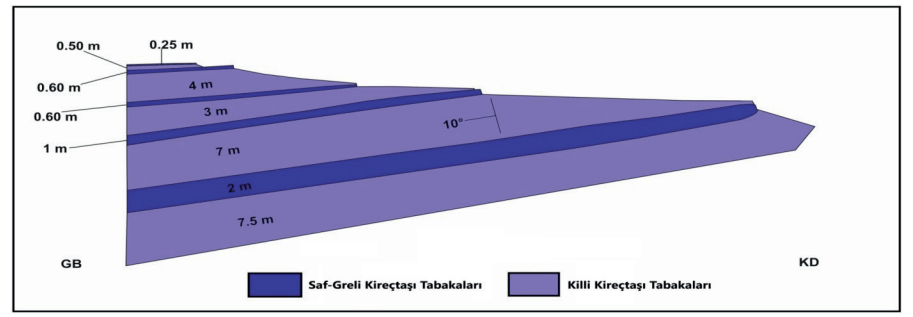

Şekil 11: Sinanköy Kuestası́nın doğu bölümüne ait stratigrafik özelliklerin şematik kesiti (Eğim değeri tüm tabakaların ortalama değerini yansıtmaktadır). Figure 11: Schematic section of stratigraphic features belonging to the east part of Sinanköy Cuesta (Slope value, represents all layers average value).

olan eğim açısı $\pm 10^{\circ}$ civarındadır. Saha çalışmalarında; formasyonların farklı direnç özelliklerine sahip birimlerin ardalanmalı bir istifi de açık olarak gözlemlenmiştir.Aynı zamanda tabakaların kalınlıklarının kısa mesafelerde değiştikleri, ondülasyonlu bir yapı sergiledikleri tespit edilmiştir. Ölçülen tabaka kalınlıklarındaki değişim; çalışma alanının doğu kısmında $0,25 \mathrm{~m}$ ile 7,5 $\mathrm{m}$ arasındayken, sahanın batı bölümünde $0,5 \mathrm{~m}$ ile 12,5 m’ler arasında olduğu görülür. Sahadaki kireçtaşı tabakalarının litolojik farklılıklarının aşınıma karşı direnç farklılıklarına neden olduğu ve vadi gelişimini etkilediği gözlemlenmiştir. Saf ve greli kireçtaşı tabakalarının aşınıma karşı nispeten daha fazla dirençli olup, kalınlıkları ise daha azdır. Buna karşın tabaka kalınlıkları daha fazla olan killi kireçtaşı tabakalarının ise aşınıma karşı dirençsiz oldukları, daha hızlı aşınıma maruz kaldıkları dikkat çeker (Şekil 11 ve 12, Fotoğraf 2 ve 3). Sahadaki litolojik birimler arasındaki bu direnç farklılığı; Şans, (2018) tarafından yapılan ölçümlerle de doğrulanmıştır.

\subsection{Yapısal Jeomorfoloji Özellikleri ve Drenaj Sistemi}

İslambeyli Formasyonu ile Kırklareli Kireçtaşı arasındaki litolojik direnç farklılığı ve tabakaların ortalama $10^{\circ}$ civarı 


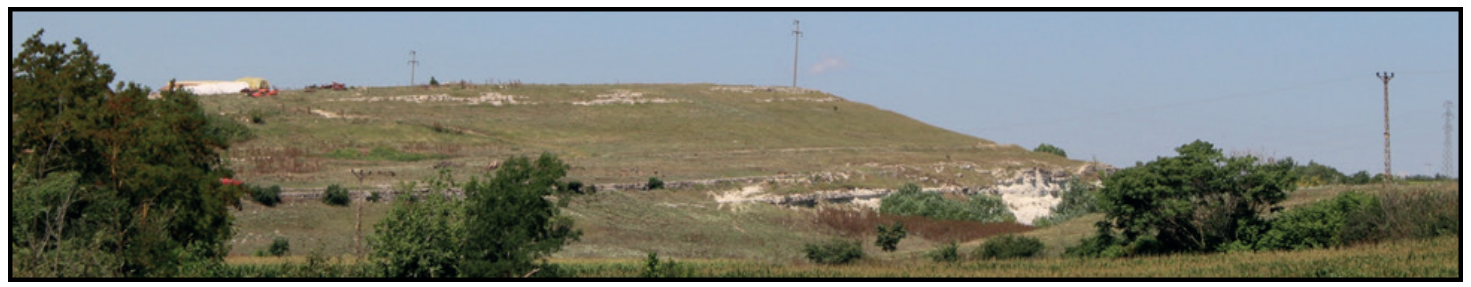

Fotoğraf 3: Sinanköy Kuestası'nın batı bölümü (Batıya bakış).

Photo 3: West part of Sinanköy Cuesta (Looking west).

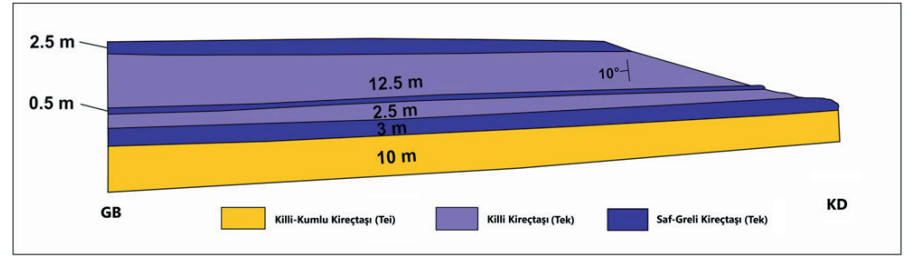

Şekil 12: Sinanköy Kuestası'nın batı bölümüne ait stratigrafik özelliklerin şematik kesiti (Eğim değeri tüm tabakaların ortalama değerini yansıtmaktadır). Figure 12: Schematic section of stratigraphic features belonging to the west part of Sinanköy Cuesta (Slope value, represents all layers average value).

güneybatıya doğru eğimli bulunmaları; Sinanköy Kuestası'nın oluşum ve gelişiminin yapısal koşullarını sağlamıştır.Sinanköy Deresi'nin 4. dizinine karşılık gelen ana kanalı, çalışma alanına kuzeydoğudan giriş yapıp, doğal eğim doğrultusu olan kuzeydoğu-güneybatı doğrultusunda, yaklaşık $4.5 \mathrm{~km}$ boyunca akış göstermektedir (Şekil 13). Sinanköy'ün hemen doğusunda sübsekant karakter kazanan Sinanköy Deresi; Kırklareli Kireçtaş1 birimlerinden oluşan dik güney yamaçlı ve kuzey yamacı İslambeyli formasyonundan oluşan daha az eğimli, yatık bir yamaç profiline sahip asimetrik sübsekant depresyona yerleşmiş ve sübsekant depresyonun gelişimine katkı sağlamıştır (Fotoğraf 4). Bu kısımda Sinanköy Deresi; İslambeyli Formasyonu'nun nispeten dirençsiz birimlerini daha hızlıca aşındırmış, daha fazla dirençli olan Kırklareli Kireçtaşı birimlerinin kuesta cephesi dikliği oluşturacak şekilde gelişmesine olanak sağlamıştır.

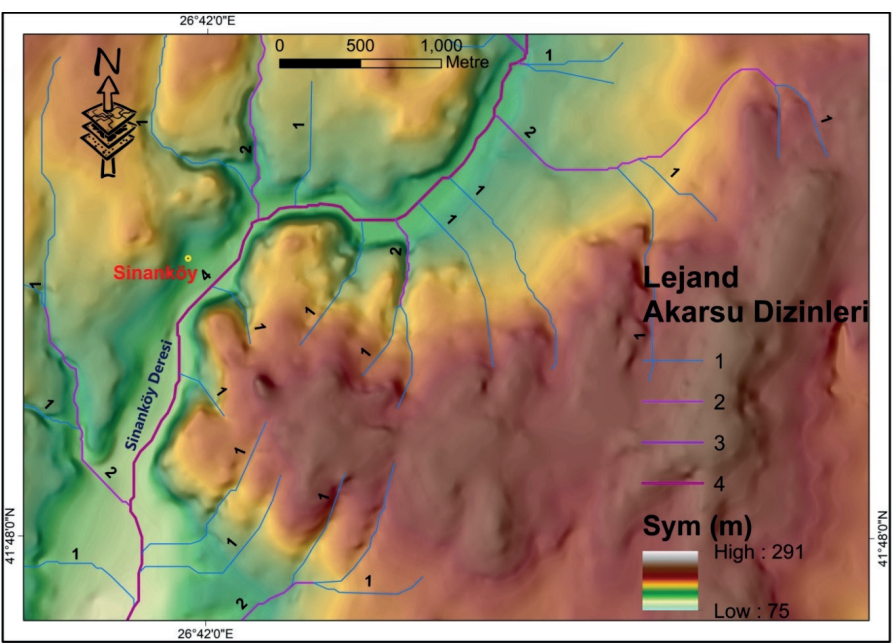

Şekil 13: Sinanköy Deresi drenaj ağı ve akarsu dizinleri.

Figure 13: Drainage network of Sinanköy Stream and stream order.
Böylece sübsekant depresyonun İslambeyli Formasyonu içinde açıldığı, kuesta cephesinin ve sırtının Kırklareli Kireçtaşı birimlerinden oluştuğu, monoklinal yapıdaki bir kuesta rölyefi meydana gelmiştir. Formasyonlar arasındaki direnç farklılığı; hangi kısımların hızlıca aşındırılacağını, hangi kısımların topoğrafyada diklik olarak kalacağını belirleyen ana kontrol edici faktör olmuştur.

Bunun yanında, tabaka kalınlıklarının, doğrultularının, eğim yönlerinin ve eğim açılarının kısa mesafelerde değişim gösterme karakterine bağlı olarak, kuesta rölyefinin de kısa mesafelerde

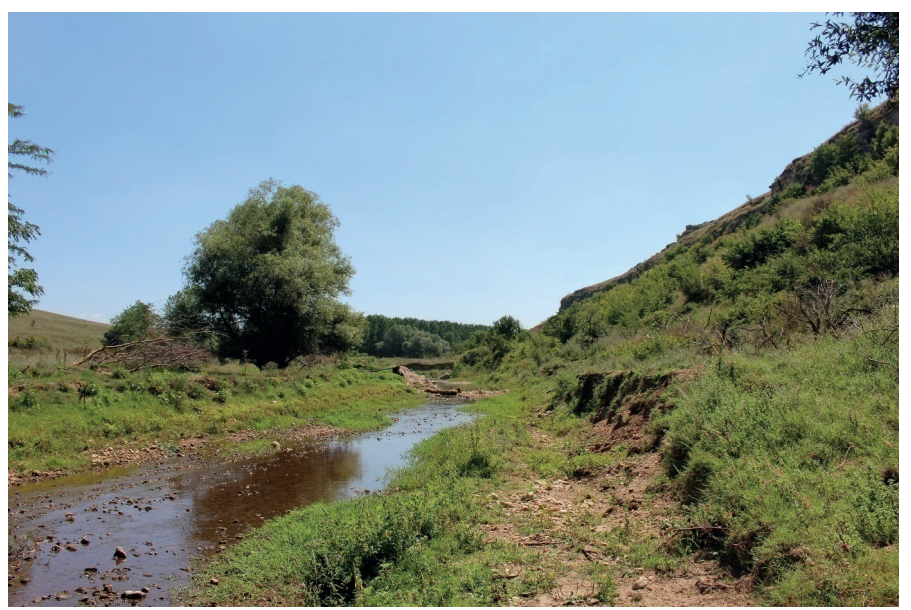

Fotoğraf 4: Sinanköy Kuestası́nın sübsekant depresyonu (Fotoğrafın sağ tarafı dik güney yamaç, sol taraf ise az eğimli kuzey yamaçtır) (Sinanköy'ün doğusu, Doğudan bakış).

Photo 4: Subsequent depression of Sinanköy Cuesta (Right side of photograph represents steeper southern slope, left side of the photograph represents less inclined northern slope) (East of Sinanköy, looking east). 
karakter değiştirdiği görülmektedir. Sinanköy Kuestası'nın batı kısmı ile doğu kısmı arasındaki litolojik, stratigrafik, jeomorfolojik farklılık bu karakteri açıkça sergilemektedir (Fotoğraf 2 ve 3).

Sinanköy Kuestası'nın cephesi, kabaca 2 km boyunca kuzeybat1güneydoğu doğrultusunda uzanım göstermektedir (Şekil 14). Batı yönünde, Kırklareli kireçtaşı (Tek) birimlerinin yapısal kontrol etkisinin zayıflamasıyla birlikte, Sinanköy Deresi keskin bir dönüşle tekrar güneybatıya yönelerek; kuesta cephesininin devamlılığını kesmiş ve burada tipik bir konsekant vadi oluşturmuştur (Şekil 13, 14). Bu konsekant vadinin tabanı, en geniş kısmında yaklaşık 300 metrelere, yamaçların dikliği ise en yüksek kısmında 50 metrelere ulaşır.

Kuesta cephesinin arkasından itibaren devam eden, üstteki dirençli kireçtaşı tabakasının da yüzeyine karşılık gelen kuesta sırtı; yaklaşık $2 \mathrm{~km}$ boyunca güneybatıya doğru eğimli bir karakterde uzanmaktadır. Kireçtaşından oluşan kuesta sırtı; sahanın bu bölümünde genel olarak 160-190 metre seviyesindeki plato yüzeyine karşılık gelmektedir. Çalışma alanındaki Trakya Formasyonu (Tnt) ve Ergene Formasyonu (Tme) gibi farklı litolojik birimlerden müteşekkil ve hafifçe güneybatıya eğimli tabaka sırtları;tipik kuesta sırtı karakterinin giderek azaldığı yapısal jeomorfoloji birimlerini teşkil etmektedir (Şekil 14).

Sinanköy ve çevresinde, sübsekant depresyonlar genel olarak doğu-batı doğrultuludur. Sinanköy Kuestası'nın sübsekant depresyonu, çok tipiktir ve genişliği 200-250 metre arasında değişirken, aynı zamanda kuesta cephesine karşı1ık gelen akış

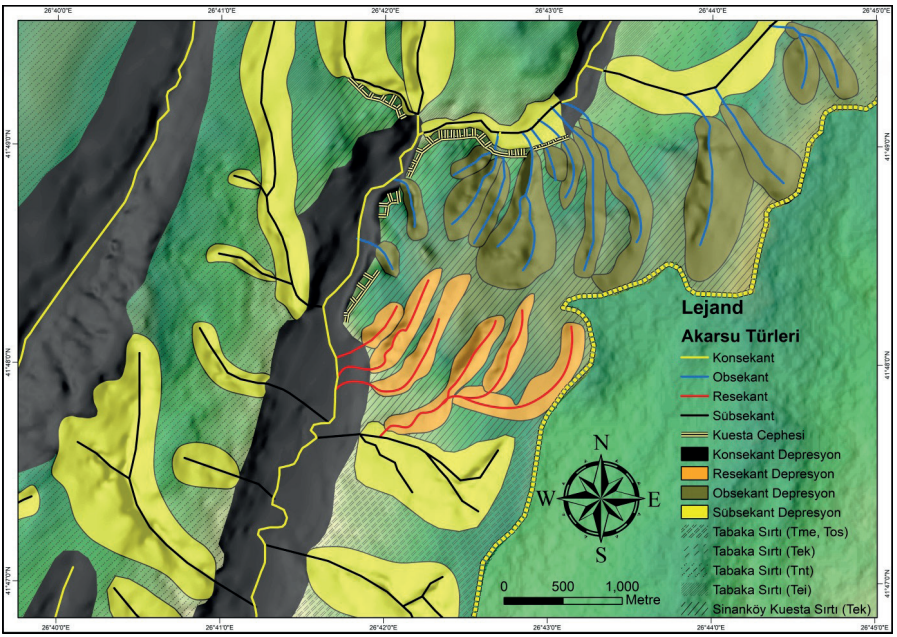

Şekil 14: Monoklinal yapı özellikleri, Sinanköy kuestası ve drenaj özellikleri.

Figure 14: Monoclinal structure characteristics, Sinanköy Cuesta and drainage features. yönüne göre daha dik olan güney yamacının yüksekliği 160 metrelere, az eğimli kuzey yamacının yüksekliği ise 130 metrelere ulaşmaktadır (Fotoğraf 4). Sinanköy ve çevresindeki diğer sübsekant depresyonlar çok tipik olmamakla birlikte;Sinanköy'ün hemen güneyi ve güneybatısında Trakya Formasyonu (Tnt) ve Ergene Formasyonu (Tme) birimleri üzerinde gelişme göstermişlerdir. İçinde bulundukları tabakaların eğim değerlerinin giderek azalmış olmaları ve direnç farklılığı etkisinin azalması tipik sübsekant vadi oluşum koşullarını ortadan kaldırmıştır. Çalışma sahasının bu bölümünde, derinlikleri 10-15m civarındaki "V" şekilli genç vadiler gelişme imkânı bulmuştur (Fotoğraf 5).

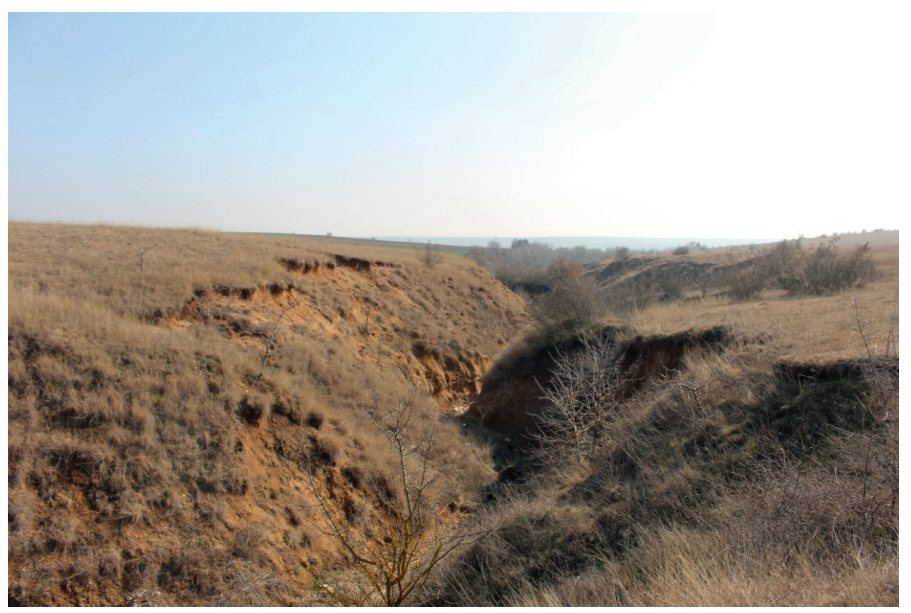

Fotoğraf 5: Trakya Formasyonu birimleri üzerinde açılmış sübsekant vadiler genç yarıntılar şeklindedir (Sinanköy'ün güneybatısı, Güneydoğuya bakış).

Photo 5: Subsequent valleys that have formed on Trakya Formation units represent young gully shapes (Southwest of Sinanköy, looking southeast)

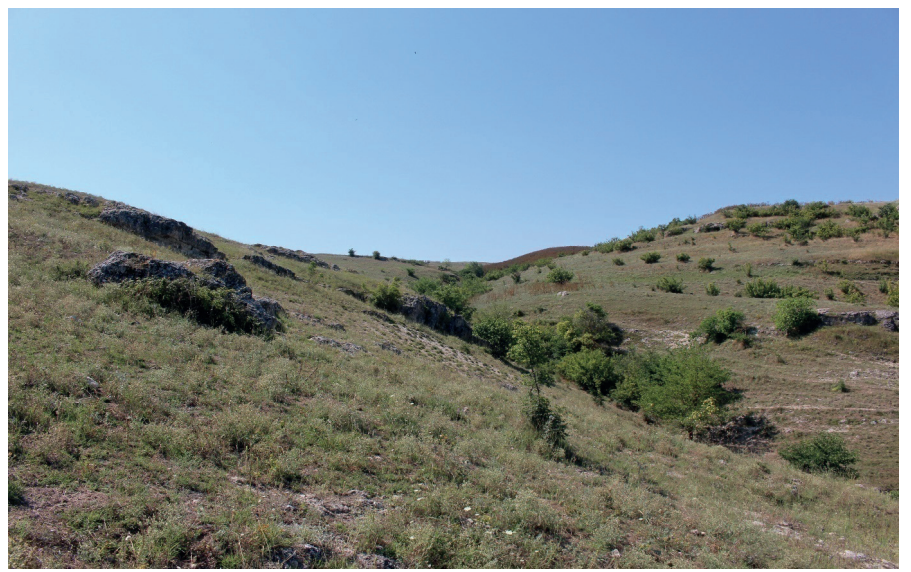

Fotoğraf 6: Çalışma sahasındaki obsekant vadilerden biri (Sinanköy'ün Doğusu, güneybatıya bakış).

Photo 6: One of the obsequent valleys in the study area (East of Sinanköy, looking southwest). 


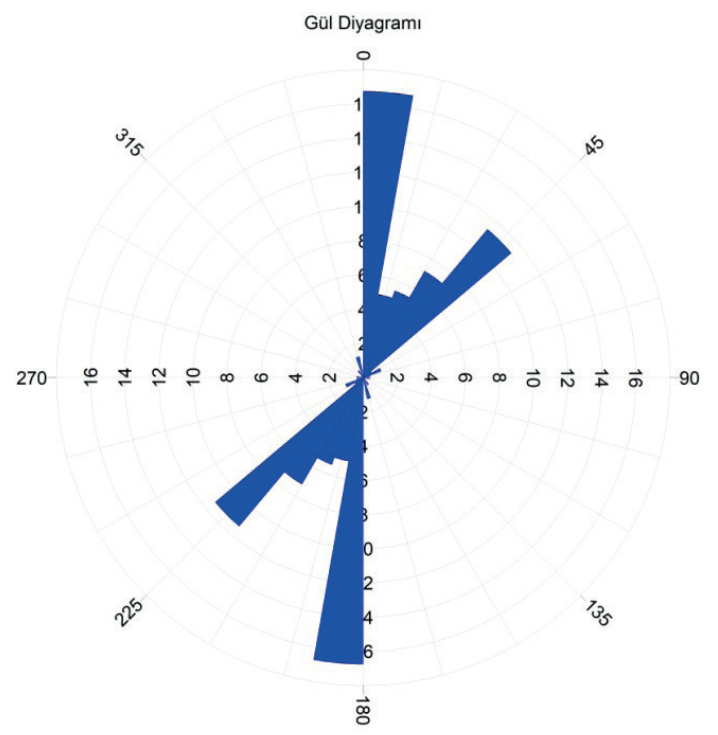

Şekil 15: Konsekant akarsuların gül diyagramı. Figure 15: Rose diagram of consequent streams.

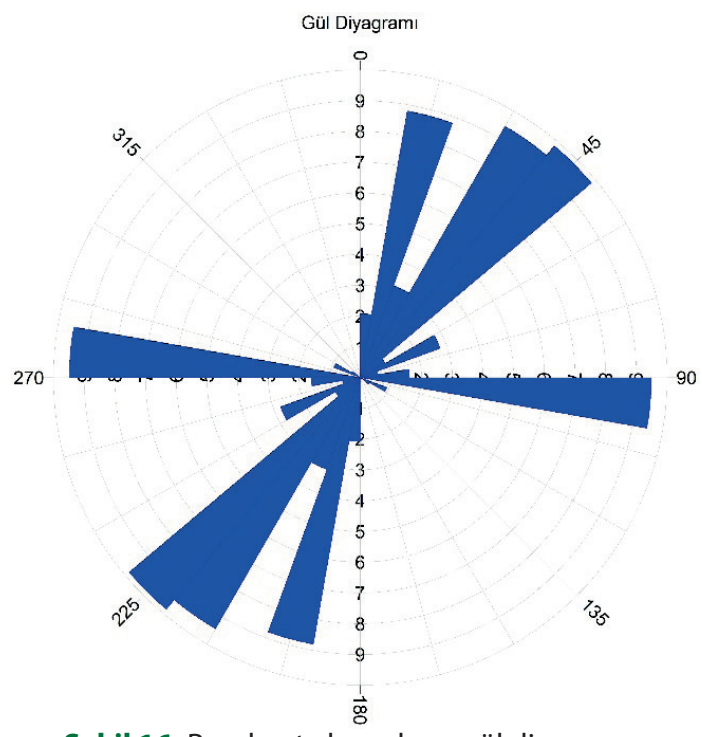

Şekil 16: Resekant akarsuların gül diyagramı. Figure 16: Rose diagram of resequent streams.

Çalışma sahasındaki konsekant depresyonların genişlikleri $150 \mathrm{~m}$ ile $1 \mathrm{~km}$ arasında değişiklik göstermektedir (Şekil 14). Obsekant depresyonlar ise Sinanköy Kuestası'nın cephesini yaracak şekilde doğu-batı ekseni boyunca kuzeydoğu-güneybatı ve kuzeybatı-güneydoğu doğrultularında dizilmişlerdir. Tabakaların doğrultularının değişmesi ile birlikte obsekant depresyonların da doğrultuları değişmektedir. Burada obsekant akarsular, Kırklareli Kireçtaşı birimlerinden meydana gelen kuesta cephesinin aralarına yerleşerek genç yarıntıları meydana getirmişlerdir (Fotoğraf 6). Bu depresyonların tabanları geniş değildir. Yamaç yükseklikleri ise 15-20 metre seviyesindedir. Aynı zamanda bu depresyonların oluşmasına neden olan süreçlerin, kuesta cephesini henüz çok geriletemediği göze

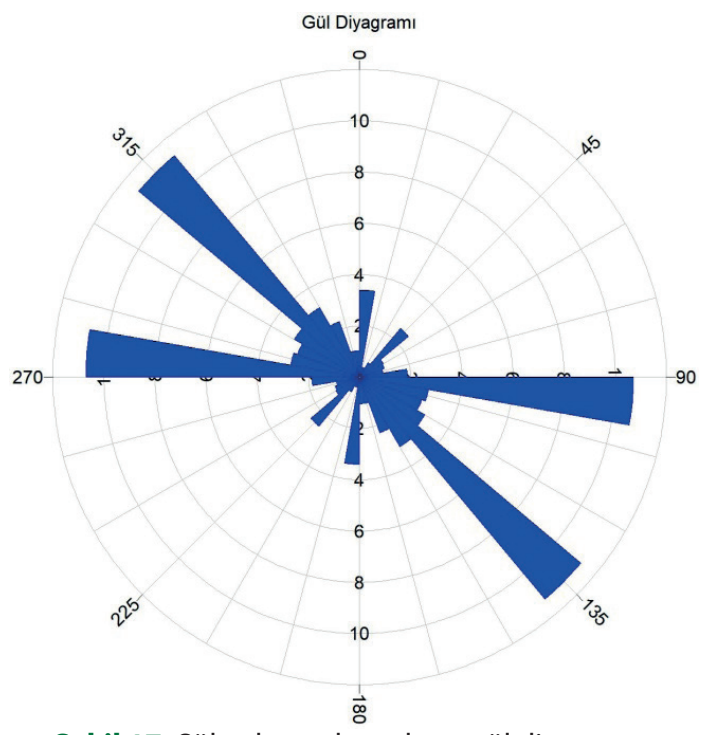

Şekil 17: Sübsekant akarsuların gül diyagramı. Figure 17: Rose diagram of subsequent streams.

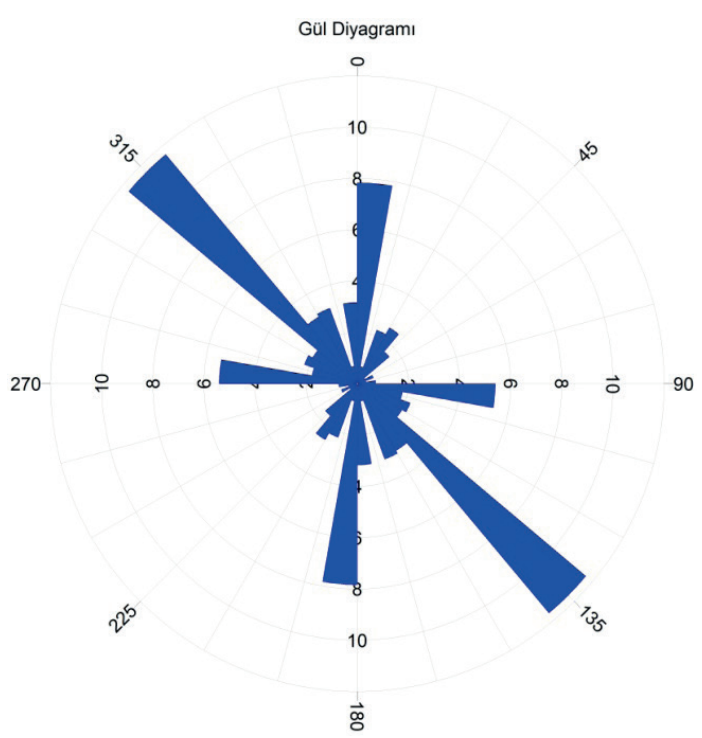

Şekil 18: Obsekant akarsuların gül diyagramı. Figure 18: Rose diagram of obsequent streams.

çarpmaktadır. Çalışma alanında herhangi bir büt veya aşınım artı̆̆ tepeye rastlanmamıştır.

Çalışma sahasındaki resekant depresyonlar da obsekant depresyonlar gibi dar tabanlı, dik yamaçlı yarma vadi özelliğindedirler. Doğal eğim yönünde akış gösteren resekant akarsularca açıldıkları için doğrultuları kuzeydoğu-güneybatıdır. Dikkat çekici farkları; obsekant depresyonlara göre daha az yarılmış olmalarıdır (Şekil 14).

Konsekant, sübsekant, resekant ve obsekant akarsular; monoklinal yapının karakteristik drenaj sisteminin üyeleridir. 
Bu akarsular monoklinal yapı üzerinde kafesli bir drenaj ağ oluştururlar. Morfometrik analizler ile çalışma sahasındaki akarsuların konsekant, sübsekant, resekant ve obsekant sınıflamaları belirlenmiştir (Şekil 14). Bu akarsuların akış yönlerine ait ayrı ayrı gül diyagramları da yapılmıştır (Şekil $15,16,17,18)$. Bu veriler dikkate alındığında; çalışma sahasında, genel eğim doğrultusunda akan ana akarsu (konsekant akarsu) Sinanköy Deresi'dir (Şekil 13, 14, 15). Ona doğu ve batıdan kabaca dik açılarla birleşen, daha az dirençli birimler içine yerleşmiş yan kollar, sübsekant akarsuları temsil etmektedir (Şekil 13, 14, 17). Konsekant akarsuya ters yönde akan ve sübsekant akarsuyla birleşen obsekant akarsular (Şekil $13,14,18)$ ile tabaka sirtlarından konsekant akarsuyla aynı yönde akan ve sübsekant akarsuyla birleşen daha kısa boylu akarsular resekantlardır (Şekil 13, 14, 16). Konsekant akarsu vadilerinin tabanlı vadi karakterinde (Şekil 9/4, 13, 14), sübsekant akarsu vadilerinin ise asimetrik vadi karakterinde oldukları (Şekil 9/2, 13, 14), obsekant ve resekant akarsu vadilerinin ise kabaca çentik vadi karakteri taşıdığ1 belirlenmiştir (Şekil 9/1-2, 13, 14).

\section{SONUC}

Bu çalışma; Sinanköy ve çevresinde gerçekleştirilmiş olup, sahanın yapısal jeomorfoloji özellikleri, yüzeysel drenaj ağı etkileşimi ve bu etkileşimin jeomorfolojik delilleri araştırılmıştır. Saha çalışmalarında gerçekleştirilen tabaka istif ve kalınlıkları, eğim, doğrultu ölçümleri ve bu ölçümlerin istatistiksel diyagramları bu etkileşimin delillerinden bir grubunu temsil etmektedir. $\mathrm{Bu}$ araştırma kapsamında gerçekleştirilen morfometrik analizler, çizgisellik analizleri, hidrolojik analizler ve bu analizlerin istatistiksel gül diyagramları ise diğer morfolojik delilleri oluşturmaktadır. Bilgisayar ortamında gerçekleştirilen analiz sonuçları, saha ölçümleri ve bunlara dayanan analiz sonuçları ve bunların birlikte ilişkilendirilmesi; çalışma sahasının hem monoklinal yapı jeomorfolojisini ve hem de onun kontrol ettiği drenaj sistemini tanımlamakta ve delillendirmektedir. Doğal akım birikimi ve doğal akım yönü analizine ait drenajın morfometrik analiz sonuçları ile uyumluluk göstermesi ve vadi kesitlerinin konsekant, sübsekant, resekant ve obsekant akarsu enkesit özelliklerini tanımlaması dikkat çekici bir tespittir. Ayrıca, akarsu gül diyagramlarındaki yönelimlerin; hem tabakaların uzanış doğrultularını temsil eden gül diyagramı ve hem de çalışma sahasındaki çizgiselliklerin gül diyagramı ile uyumlu olarak çakışması, mevcut drenaj sisteminin, çalışma sahasının yapısal jeomorfoloji özellikleri ile uyumlu olduğunun açık kanıtlarını oluşturmaktadır.
Yapılan tüm analizler ve saha ölçümlerine göre, çalışma sahasındaki drenaj ağı; litoloji ve monoklinal yapı kontrol unsurlarına bağlı gelişmiş ve akarsu süreçleri etkinleştikçe monoklinal yapı şekilleri topoğrafyada daha fazla belirginleşerek bugünkü görünümlerini kazanmışlardır. Yapı kontrolünde gelişen kafesli (ortogonal) drenaj ağı flüviyal etkinliğini geliştirdikçe bu durum; sahada kuestalar, sübsekant, obsekant, resekant depresyonlar, kuesta sırtı düzlükleri gibi monoklinal yap1 elemanter yer şekillerinin daha belirgin olarak ortaya çıkmasına neden olmuştur.

Hakem Değerlendirmesi: Dış bağımsız.

Çıkar Çatışması: Yazarlar çıkar çatışması bildirmemiştir.

Finansal Destek: Yazarlar bu çalışma için finansal destek almadığını beyan etmiştir

Peer-review: Externally peer-reviewed.

Conflict of Interest: The authors have no conflict of interest to declare.

Grand Support: The authors declared that this study has received no financial support.

\section{KAYNAKLAR}

Andreani, L., Stanek, P., Gloaguen K., Krentz R., \& DominguezGonzales O. (2014). DEM-based analysis of interactions between tectonics and landscapes in the Ore Mountains and Eger Rift, Remote Sensing, 6(9), 7971-8001.

Ardel, A. ve Tümertekin, E. (1956). Trakya'da coğrafi müşahedeler. Türk Coğrafya Dergisi, 15-16, 1-20.

Ardel, A. (1957). Trakya'nın Jeomorfolojisi. Türk Coğrafya Dergisi, $17,152-158$.

Ardos, M. (1995).Türkiye Ovalarının Jeomorfolojisi Cilt 1, Çantay Kitabevi, 2. Bask1, İstanbul.

Aykut T. (2018).Kaynarca Dere Havzası Akarsularının Gelişiminde Yapısal Faktörlerin Etkisi [Öz]. Tücaum 30. Y1l Uluslararas1 Coğrafya Sempozyumu'nda Sunulan Bildiri, Ankara Üniversitesi. Erişim adresi:http://kitaplar.ankara.edu.tr/detail.php?id=920.

Aykut, T. (2019). Edirne-Hamzabeyli-Kalkansöğüt Arasının Yapısal Özelliklerinin Uygulamal Jeomorfoloji Üzerine Etkileri. (Basılmamış Yüksek Lisans Tezi). İstanbul Üniversitesi Sosyal Bilimler Enstitüsü, İstanbul.

Azanon, J.N., Galve J.P., Perez-Pena J.V., Giaconia F., Carvajal R., Booth-Rea R., Jabaloy A., \& Roldan F.J. (2015). Relief and drainage evolution during the exhumation of the Sierra Nevada (SE Spain): Is denudation keeping pace with uplift?Tectonophysics, 663, 19-32.

Bull, W. B. (1977). Tectonic geomorphology of the Mojave Desert. U.S Geological Survey Contact Report 14-08-001-G-394. Menlo Park, CA: Office of Earthquakes, Volcanoes, Engineering.

Bull, W. B. (1978). Geomorphic tectonic classes of the south front of the San Gabriel Mountains, California. U.S. Geological Surfey Contact Report 14- 08-001-G-394. Menlo Park, CA: Office of Earthquakes, Volcanoes, Engineering. 
Burchfiel, B.C., Nakov, R., Dumurdzanov, N., Papanikolau, D., Tzankov, T., Serafimovski, T., King, \& Nurce, B. (2008). Evolution and dynamics of the Cenozoic tectonics of the South Balkan extensional system, Geosphere, 4(6), 919-938.

Çağlayan, A.M. ve Yurtseven, A. (1998), 1/100.000'lik Jeoloji Haritalarl Raporu. Burgaz-A3, Edirne-B2 ve B3; Burgaz A-4 Paftaları. MTA Genel Müdürlüğü, Ankara.

Davis, W.M. (1899). The drainage of cuestas. Proceedings of the Geologists'Association, 16, 87-93.

Dimitriadis, S., Kondopoulou, D., Atzemoğlu, A. (1998). Dextral rotations and tectonomagmatic evolution of the southern Rhodope and adjacent regions (Greece), Tectonophysics, 299, 159-173.

Erinç, S. (2015). Jeomorfoloji 1; 5. Bask1, Der Yayınları, İstanbul.

Keller, E.A., Pinter, N. (2002). Active Tectonics Earthquakes, Uplift, and Landscape, Second Edition, Prentice Hall, New Jersey.

Keskin, C. (1974), Kuzey Ergene Havzası'nın Stratigrafisi, Okay, H., ve Dileköz. E., (Ed.), Türkiye 2. Petrol Kongresi Tebliğleri, Ankara, 137-163.

Kilias, A., Falalakis, G., Sfeikos, A., Papadimitrou, E., Vamvaka A., \& Gkarlaouni, C. (2013). The Thrace basin in the Rhodope province of NE Greece - A tertiary supradetachment basin and its geodynamic implications, Tectonophysics, 595-596, 90-105.

Kurter A. (1967). Çayırdere Kuestası, İstanbul Üniversitesi Coğrafya Enstitüsü Dergisi, 16, 144-149.

Kurter A. (1978). Istranca (Yıldız) Dağları'nın temel yapısal ve jeomorfolojik özellikleri (yeni görüşlerin 1şı̆̆ında) I, Güneydoğu Avrupa Araştırmaları Dergisi, 6-7, 1-26, İstanbul.

Kurter, A. (1982). Istranca (Yıldız) Dağları'nın Temel Yapısal ve Jeomorfolojik Özellikleri (Yeni Görüşlerin Işığında) II, Güneydoğu Avrupa Araştırmaları Dergisi, 10-11, 1-19, İstanbul.

Morisawa, M. (1987). Structure and geomorphology. In: Seyfert, C. (Ed.). Structural Geology and Tectonics. Encyclopedia of Earth Science. Springer, Berlin, Heidelberg.

Maden Tetkik ve Arama Genel Müdürlüğü. (2006). Trakya bölgesi litostratigrafi birimleri. Ankara.

Özdemir, H. (2011). Havza morfometrisi ve taşkınlar. D. Ekinci (Ed.) Fiziki coğrafya araştırmaları: sistematik ve bölgesel kitab1 içinde (s.507-526). İstanbul: Türk Coğrafya Kurumu Yayınları.

Paul, D. J., Watson, N., Tuckwell, E. (2018), Comparison between scarp and dip-slope rivers of the Cotswold Hills, UK, Proceedings of the Geologists Association, 129(1), 57-69.

Perinçek, D.: (1991), Possible strand of the North Anatolian Fault in the Thrace Basin, Turkey - An Interpretation, AAPG Bulletin, 75, 241257.
Petit F., Maquil R., Kausch B., Hallot E. (2018). Cuestas in Gutland (S Luxembourg) and Belgian Lorraine: Evolution of a Structurally Controlled Landscape, In A. Demoulin (Ed.), Landscapes and Landforms of Belgium and Luxembourg; World Geomorphological Landscapes, Springer International Publishing, 395-410.

Pike, R.J. ve Wilson, S.E. (1971). Elevation-relief Ratio, Hypsometric Integral and Geomorphic Area-altitude Analysis, Geological Society of America Bulletin, 82, 1079-1083.

Rana, N., Singh, S., Sundriyal, P. Y., Rawat, S.G., \& Juyal, N. (2016). Interpreting the geomorphometric indices for neotectonic implications: An example of Alaknanda valley, Journal of Earth System Science, 125(4), 841-854.

Schumm, S.A.: (1956). Evolution of drainage systems and slopes in badlands at Perth Amboy, New Jersey, Geological Society of America Bulletin, 67, 597-646.

Selim, H. H. (2013). Tectonics of the buried Kirklareli Fault, Thrace Region NW Turkey,Quaternary International, 312, 120-131.

Strahler, A. N. (1952). Hypsometric (area-altitude curve) Analysis of Erosional Topography, Geological Society of America Bulletin, 63, $1117-1141$.

Summerfield, M. (1991). Global Geomorphology. Longman, Edingburgh.

Şans, B. E. (2018). Kuzeybatı Trakya'da (Lalapaşa-Pınarhisar) Íslambeyli Formasyonu'nun ve Bentonit Oluşumlarının Jeolojisi, Mineralojisi, Jeokimyasi ve Teknolojik Özellikleri. (Doktora Tezi). İstanbul Teknik Üniversitesi Fen Bilimleri Enstitüsü, İstanbul.

Turgut, S. ve Atalık, E. (1988). Thrace Basin: an extensional Tertiary sedimentary basin in an area of major plate convergences, northwest Turkey, American Association of Petroleum Geologists Bulletin, Volume 72, 9.

Turoğlu, H. (1997). İyidere Havzasının Hidrografik Özelliklerine Sayısal Yaklaşım, Türk Coğrafya Dergisi, 32, 355-364.

Turoğlu, H. ve Aykut, T. (2019). Ergene Nehri Havzası için Hidromorfometrik Analizlerle Taşkın Duyarlılık Değerlendirmesi, Jeomorfolojik Araştırmalar Dergisi, 2, 1-15.

Twidale, C.R. (2004). River patterns and their meaning, EarthScience Reviews, 67(3-4), 159-218.

Y1lmaz, P. O. (1988). Tectonic framework of Turkish sedimentary basins, American Association of Petroleum Geologists Bulletin, Volume 72, Page 9.

Yalçınlar, İ. (1958), Strüktüral morfoloji 1. İstanbul: İstanbul Üniversitesi Coğrafya Enstitüsü Yayınları No: 24.

Yildırım, C. (2014). Relative tectonic activity assessment of the Tuz Gölü Fault Zone; Central Anatolia, Turkey, Tectonophysics, 630, 183-192. 